\title{
The Analysis of Comparison Electrical Power Measurement on LED Lamps
}

\author{
Prisma Megantoro ${ }^{1}$, Geston Bakti Muntoha ${ }^{2}$, Kunal Kunal ${ }^{3}$, Phong Thanh Nguyen $^{4}$, Elsayed T. Helmy ${ }^{5}$ \\ 1,2 Department of Electrical Engineering and Informatics, Universitas Gadjah Mada, Yogyakarta, Indonesia \\ ${ }^{3}$ School of Information, Communication \& Technology, Indraprastha University, Delhi, India \\ ${ }^{4}$ Director, Department of Project Management, Ho Chi MinhCity Open University, Vietnam \\ ${ }^{5}$ National Institute of oceanography and fisheries, Alexandria \\ gestonbakti@mail.ugm.ac.id, Kunal.karn007@gmail.com,phong.nt@ou.edu.vn, stalaat41@gmail.com
}

\begin{abstract}
This study uses 2 variations of the value of the DC $12 \mathrm{~V}$ LED lamp power that is $12 \mathrm{~W}$ and $15 \mathrm{~W}$ with 3 different brands of lamp variations. Measurement of input voltage and current is carried out using a Krisbow KW06-490 DC clampmeter that has been calibrated as a standard measuring instrument and a Krisbow KW06-491 DC clampmeter that has not been calibrated as a test gauge 1 and a Multimeter Viper DT830B that has not been calibrated as a test gauge 2. Data the current and input voltage between each lamp and different lamp brands are used to calculate the value of the test lamp power and then compare it. The big conclusion from this study was found that the error value between the value of the test power or the use of DC 12V LED lamps with $12 \mathrm{~W}$ written power on $R, S$, and $T$ brand lamps was $\pm \mathbf{5 1 . 6 7 \%}, \pm \mathbf{7 0 . 7 5 \%}, \pm 61.33 \%$. In $15 \mathrm{~W}$ lamps the brands $R, S$, and $T$ were $\pm 7.20 \%, \pm 0.53 \%, \pm 8.27 \%$.
\end{abstract}

Keywords - voltage, current, power measurement, error

\section{INTRODUCTION}

Electrical energy is one form of energy that is needed by humans [1] - [4]. Electrical energy is used by humans as an energy source for equipment to help with any work [5] - [7]. One form of utilization of electrical energy is for lighting equipment sources such as lights as lighting sources at night. Devices that require electrical energy sources also have a certain electrical energy consumption in accordance with the power needed for these devices to operate [8] - [11]. These parameters need an audit so that the correctness of the device's power is in accordance with the specifications so that users can adjust electrical energy consumption. This can be done with the measurement process. Metrology is a science related to measurement. Everyday life of every human being is never separated from the wholeness and knowledge of metrology in the field of measurement, evaluation, and weighing [12] - [17]. Similarly, the industrial sector requires tools that can measure accurately to determine the quality standards of a product through a calibration process [18] [25]. This also occurs in one form or type of industrial products in the electric magnitude sector, namely LED lights (Light Emitting Diode) [24] - [28] DC 12V, where the power specifications written on the product must be in accordance with the actual value so that there is no loss to consumers who use the product as a device in a home lighting system.

The selection of this type of lamp because this type of lamp is one of the emergency lights used as lighting when the
AC source from PLN does not exist with a substitute source that is easy to find or commonly used by the public that is the type of accumulator or $12 \mathrm{~V}$ DC battery whose use is often found as a source of electricity on the bicycle motorcycle that is easy to find.

Based on these problems, the authors do this research, which can later find out the truth of the power value of a DC $12 \mathrm{~V}$ LED lighting product in a variety of different lamp brands with the same power specifications.

\section{METHOD}

This chapter discusses the components needed for testing, the measurement tools used, and the data collection methods and methods for testing them.

The time and place of research will be conducted in the second week of February 2018 at the designated place, namely the Metrology Instrumentation Laboratory, Vocational School, Gadjah Mada University, Yogyakarta.

Multimeter [29] - [31] or multitester (analog) is a device that is generally used to measure the quantities of voltage (AC, DC), strong currents [32] - [36] (usually DC only), and resistance. In accordance with its function the multimeter is also called the AVO-meter, which is an Ammeter, Voltmeter and Ohmmeter. Basically, a multimeter uses a D'Arsonval type current meter. The basic specification in choosing a multimeter is its sensitivity or sensitivity [37] - [40]. Sensitivity is related to the loading effect on the measured circuit.

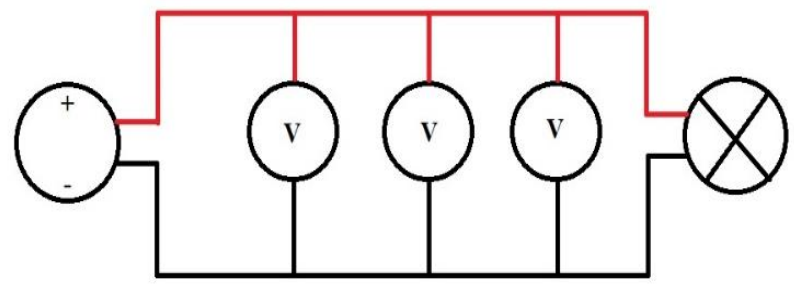

Fig. 1. Electric current measurement scheme

V1 is a calibrated standard measurement device, V2 and $\mathrm{V} 3$ are tested measurement device. 


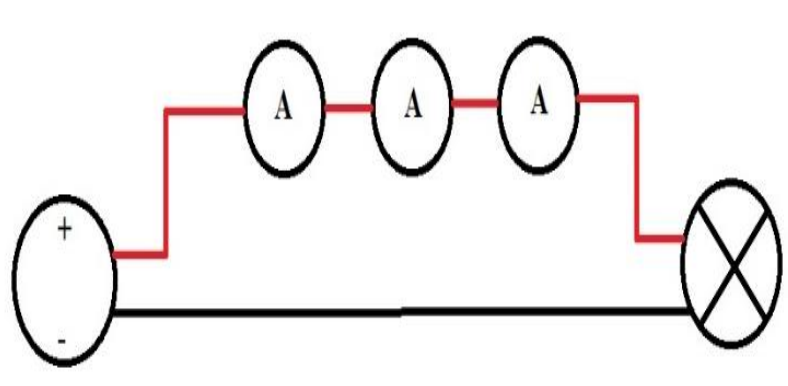

Fig. 2. Electric voltage measurement scheme

A1 is a calibrated standard measurement device, A2 and A3 are tested measurement device. In Figure 1 and Figure 2 is an illustration of a voltage and current testing scheme with a voltage source originating from a DC Power Supply which is regulated at an output voltage of $12 \mathrm{~V}$. Standard measuring devices as well as test 1 and measuring instrument test 2 are arranged to measure the output voltage from DC Power Supply with a parallel connection, while the connection in series is used to measure electric current. DC Clampmeter measuring tool with the function of voltage and current measurement namely Krisbow KW06-490 which has been calibrated is used as a standard measuring instrument, while the DC Clampmeter Krisbow KW06-491 measuring tool that has not been calibrated with the voltage and current measuring function as a test measure 1 and multimeter Viper DT $830 \mathrm{~B}$ which has not been calibrated with the function of measuring voltage and current as a test gauge 2 .

\section{Data processing}

The data processing technique in this research is that the research only focuses on comparing the value of the input voltage reading and the current readings of each lamp and different lamp brands with the same specifications, namely DC $12 \mathrm{~V} 12 \mathrm{~W}$ and $15 \mathrm{~W}$. The test will be carried out using a repetition method which is carried out 20 times on each lamp and a different lamp brand.

\section{Data analysis}

Data analysis techniques from this research are using Analysis of the calculation of the error between the digital multimeter designation and the test clampmeter with a standardized calibrated measuring instrument. The percentage of error in a measurement of a quantity can be calculated using equation 1 .

$$
\text { Error }=\left(\frac{\text { standart-tested }}{\text { standart }}\right) \times 100 \%
$$

Analysis of the calculation of the error between the test power with the written power on the packaging or lamp specifications. Graph analysis of test results. Comparative analysis of current value and direct test power. Comparative analysis of current and power values in direct testing between lamp brands.

\section{RESULT AND DISCUSSION}

Research on measuring the value of power on DC $12 \mathrm{~V}$ LED lights, using lamps with the same specifications with different brands. Variations are also made not only on the brand but also on the value of the lamp power that is equal to 15 Watt and 12 Watt on each brand of lights. The voltage reading results on the multimeter voltmeter and current on the ammeter and clampmeter are used to calculate the power value.

The study uses variations of R, S, and T lamp brands, each with a power value of 15 and 12 Watt.

\section{Voltage and current measurement on LEDs 12 VDC}

Voltage measurement using 3 measuring devices with different voltage measurement functions, namely Krisbow KW06-490 which has been calibrated as a standard measuring instrument and as a comparison of the results of voltage measurements on other measuring devices used, Krisbow KW06-491, and Viper DT830B which is installed or used to measure at the same time as a comparison test measuring instrument standard measurement results by pairing it in parallel at the lamp input voltage. Current measurement using 3 measuring devices with different DC current measurement functions, namely Krisbow KW06-490 which has been calibrated as a standard measurement tool and as a comparison of the results of measuring the current in other measuring devices used by means of pinning positive or red wire on the lamp to measure the value currents, Krisbow KW06-491 installed or used to measure at the same time as a measuring instrument comparative test standard measurement results are also the same, namely by clamping or clamping the positive cable or red color on the lamp to measure the current value, and Viper DT830B installed or used to measure at once as a comparison test measuring instrument standard measurement results with a current measuring function but installed or measured using the multimeter probe whose configuration is in series on the positive wire or red color on the lamp to measure the current value. From the data obtained, the value of the input voltage read on each lamp sample has a value of around $\pm 11.6 \mathrm{~V}$ from the voltage setting on the DC power supply of $12 \mathrm{~V}$.

The difference in input voltage readings are caused by one of them being the type of DC power supply that is used to have an output voltage regulation manually by turning the output voltage knob until the output reading value on the indicator display on the LCD is valued at $12 \mathrm{~V}$, so the DC power supply output voltage value is not necessarily right at $12 \mathrm{~V}$. On the average input voltage reading of DC $12 \mathrm{~V}$ brand LED lights with 12 Watt power on 3 different multimeters namely $(11.60 \pm 1.04)$ Volts, $(11.61 \pm 1.24)$ Volts, $(11,61 \pm$ 1.32) Volt, the average input voltage reading of LED brand $12 \mathrm{~V}$ DC lights with $12 \mathrm{Watt}$ power on 3 different multimeters is equal to $(11.70 \pm 1.05)$ Volts, $(11.71 \pm 1.55)$ Volt, $(11.69$ $\pm 1.64)$ Volt, the average input voltage reading of a $12 \mathrm{~V} \mathrm{DC}$ LED T brand with 12 Watt power on 3 different multimeters is $(11.60 \pm 1.07)$ Volts, $(11.69) \pm 1.26)$ Volts, $(11.66 \pm 1.51)$ Volts. The average input voltage of a $12 \mathrm{~V}$ DC R brand LED lamp with 15 Watt power on 3 different multimeters is equal to $(11.60 \pm 1.09)$ Volts, $(11.66 \pm 1.62)$ Volts, $(11.65 \pm 1,82)$ Volt, the average input voltage reading of a S $12 \mathrm{~V}$ DC LED lamp with 15 Watt power at 3 different multimeters is (11.6 $\pm 1.09)$ Volts, $(11.69 \pm 1.31)$ Volts, $(11,67 \pm 1.49)$ Volt, the average input voltage reading of a $\mathrm{T} 12 \mathrm{~V}$ DC LED lamp with 15 Watt power at 3 different multimeters is $(11,60 \pm 1.08)$ 
Volts, $(11.65 \pm 1.27)$ Volts, $(11.66 \pm 1.58)$ Volts. Voltage readings are presented in Figure 3 and Figure 4.

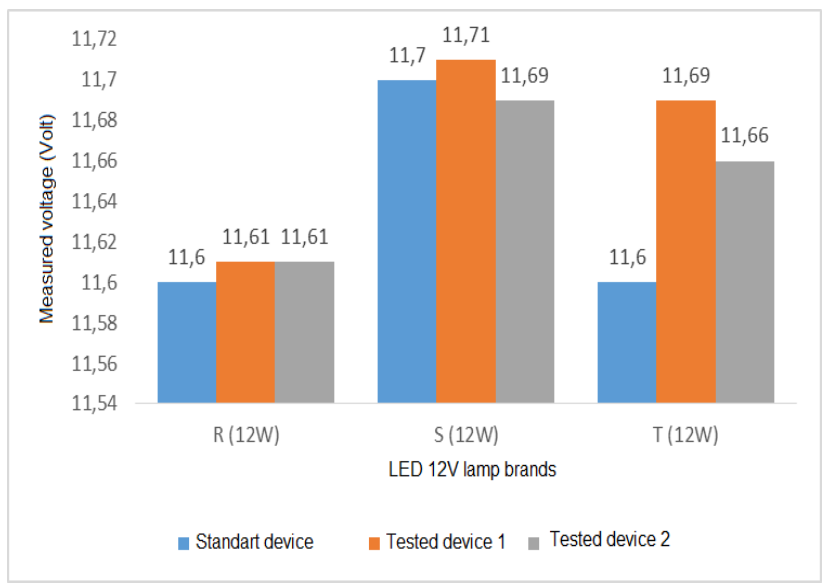

Fig. 3. Average measured voltage on LED $12 \mathrm{~V}$ histogram

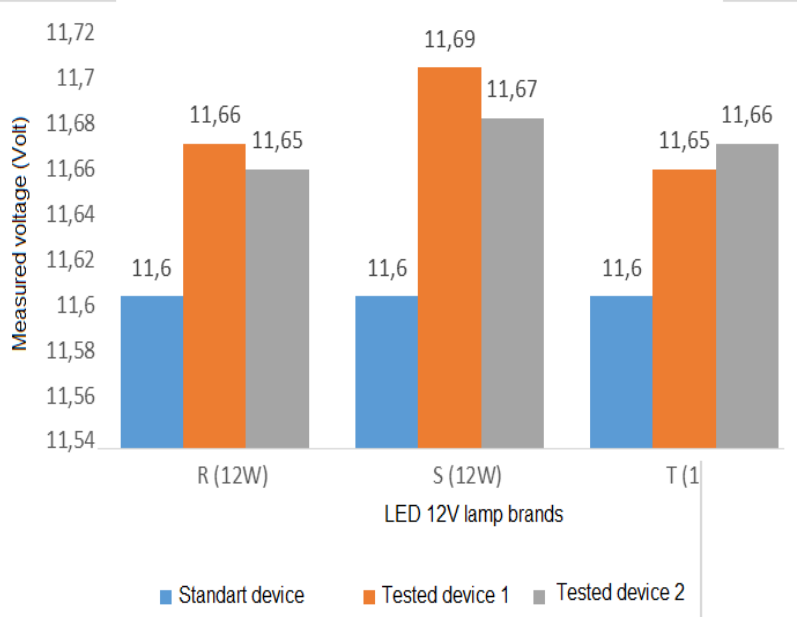

Fig. 4. Average measured voltage on LED 15V histogram

From the data obtained, the current value read in each lamp sample has a different value. The difference in current readings is caused by one of them being the circuit scheme or configuration of the leds on the lamps as well as the number of leds and the characteristics of the leds used by each brand of lights, so the current rating reads for each lamp becomes different.

On the average current reading of DC $12 \mathrm{~V}$ LED lights $\mathrm{R}$ brand with 12 Watt power on 3 different multimeters namely $(0.50 \pm 0.60)$ Ampere, $(0.57 \pm 1.40)$ Ampere, $(0.57 \pm 1,64)$ Ampere, the average current reading of a S $12 \mathrm{~V}$ DC brand with 12 Watts of power at 3 different multimeters is $(0.30 \pm$ $0.35)$ Ampere, $(0.34 \pm 1.32)$ Ampere, $(0,39 \pm 1.56)$ Amperes, the average current reading of LED lights $12 \mathrm{~V}$ brand $\mathrm{T}$ with 12 Watt power on 3 different multimeters that is equal to $(0.40 \pm 0.78)$ Ampere, $(0.43 \pm 1.58)$ Ampere, $(0.45$ $\pm 1.54)$ Ampere.

On the average current reading of DC $12 \mathrm{~V}$ LED lights R brand with 15 Watt power in 3 different multimeters namely $(1.20 \pm 0.59)$ Ampere, $(1.28 \pm 1.76)$ Ampere, $(1.32 \pm 1,79)$ Amperes, while the average current reading of DC S $12 \mathrm{~V}$ brand LEDs with 15 Watt power at 3 different multimeters is $(1.30 \pm 0.38)$ Ampere, $(1.33 \pm 1.49)$ Ampere, $(1.39 \pm 1.71)$
Ampere, the average current reading of a $12 \mathrm{~V}$ DC LED T brand with 15 Watt power on 3 different multimeters is (1.40 \pm 0.74) Ampere, $(1.43 \pm 1,53)$ Ampere, $(1.44 \pm 1.74)$ Ampere. Flow readings are presented in Figure 5 and Figure 6.

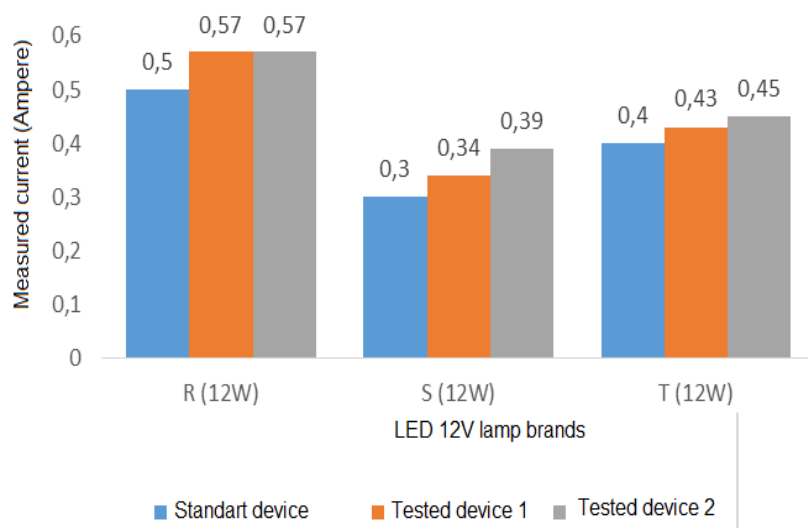

Fig. 5. Average measured current on LED $12 \mathrm{~V}$ histogram

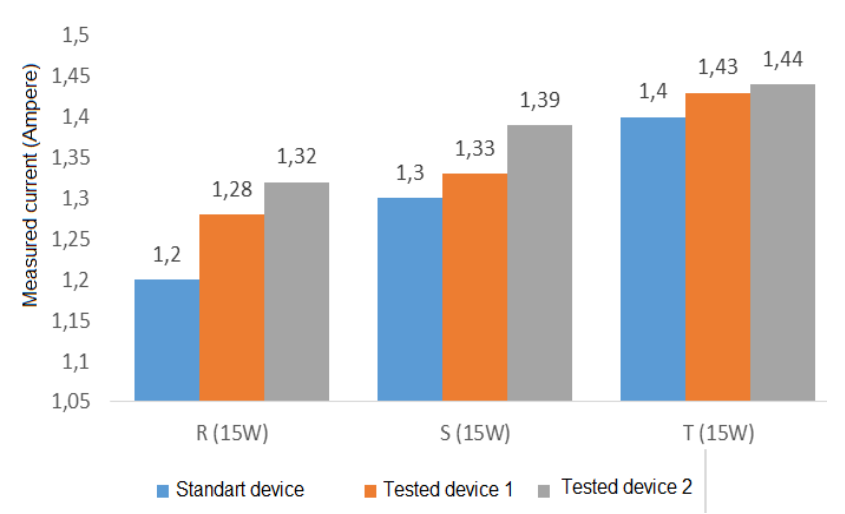

Fig. 6. Average measured current on LED 15V histogram

\section{Error analysis}

Errors regarding specifications are obtained only through the results of comparisons between the power values read by the Krisbow KW06-490 standard DC clampmeter that has been calibrated with the written power values on the DC $12 \mathrm{~V}$ LED lamp specifications printed on the lamp package. Comparison of errors presented in Table 1.

TABLE I. Power ERror Measurement Test Of The Standart And TESTED

\begin{tabular}{|c|c|c|}
\hline Brand & $\begin{array}{c}\text { Power } \\
(\mathrm{W})\end{array}$ & $\begin{array}{c}\text { Error } \\
(\%)\end{array}$ \\
\hline \multirow{2}{*}{$\mathrm{R}$} & 12 & 51,67 \\
\cline { 2 - 3 } & 15 & 7,2 \\
\hline \multirow{2}{*}{$\mathrm{S}$} & 12 & 70,75 \\
\cline { 2 - 3 } & 15 & 0,53 \\
\hline \multirow{2}{*}{$\mathrm{T}$} & 12 & 61,33 \\
\cline { 2 - 3 } & 15 & 8,27 \\
\hline
\end{tabular}

\section{CONCLUSIONS}

From the research that has been done, the following conclusions are obtained. The value of the error reading 
power on the test gauge with LED $12 \mathrm{~V}$ DC brand specifications with $12 \mathrm{~W}$ power on 2 test measuring devices that is equal to $\pm 13.16 \%$ and $\pm 13.76 \%$. In the $S$ brand with a $12 \mathrm{~W}$ power of $\pm 12.86 \%$ and $\pm 28.58 \%$, while in the $\mathrm{T}$ brand with a $12 \mathrm{~W}$ power of $\pm 9.1 \%$, and $\pm 13.43 \%$. Measurement of the value of the error reading power on the test gauge with LED $12 \mathrm{~V}$ DC brand specifications with $15 \mathrm{~W}$ power on 2 test measuring devices that is equal to $\pm 7.59 \%$ and $\pm 10.76 \%$. In the $\mathrm{S}$ brand with $15 \mathrm{~W}$ power of $\pm 2.89 \%$ and $\pm 7.39 \%$, while in the $\mathrm{T}$ brand with $15 \mathrm{~W}$ power of $\pm 2.98 \%$, and $\pm 3.19 \%$. The error value between the test power value or the use of DC $12 \mathrm{~V}$ LED lights with a written power of $12 \mathrm{~W}$ on $\mathrm{R}, \mathrm{S}$, and $\mathrm{T}$ brand lights is $\pm 51.67 \%, \pm 70.75 \%, \pm 61.33 \%$. In $15 \mathrm{~W}$ lamps the brands $\mathrm{R}, \mathrm{S}$, and $\mathrm{T}$ were $\pm 7.20 \%, \pm 0.53 \%, \pm 8.27 \%$. Lamp samples that have the closest power value to the written value for DC $12 \mathrm{~V}$ LED lamps with $12 \mathrm{~W}$ power are $\mathrm{R}$ brand lamps, while for $12 \mathrm{~V}$ DC LED lamps with $15 \mathrm{~W}$ power are $\mathrm{S}$ brand lights.

\section{REFERENCES}

[1] O. Caumont, P. Le Moigne, C. Rombaut, X. Muneret, and P. Lenain, "Energy gauge for lead-acid batteries in electric vehicles," IEEE Trans. Energy Convers., vol. 15, no. 3, pp. 354-360, 2000.

[2] B. Szabados and A. Mihalcea, "Design and implementation of a calorimetric measurement facility for determining losses in electrical machines," IEEE Trans. Instrum. Meas., vol. 51, no. 5, pp. 902-907, 2002.

[3] C. Landi, M. Luiso, and N. Pasquino, "A Remotely Controlled Onboard Measurement System for Optimization of Energy Consumption of Electrical Trains," IEEE Trans. Instrum. Meas., vol. 57, no. 10, pp. 2250-2256, Oct. 2008.

[4] A. M. Yassine, T. M. Chen, and M. Bordelon, "Resistance transients in Al-based thin films and activation energy measurements," IEEE Trans. Electron Devices, vol. 45, no. 11, pp. 2375-2378, 1998.

[5] A. D. Femine, D. Gallo, C. Landi, and M. Luiso, "Advanced Instrument For Field Calibration of Electrical Energy Meters," IEEE Trans. Instrum. Meas., vol. 58, no. 3, pp. 618-625, Mar. 2009.

[6] Yonghua Cheng, "Assessments of Energy Capacity and Energy Losses of Supercapacitors in Fast Charging-Discharging Cycles," IEEE Trans. Energy Convers., vol. 25, no. 1, pp. 253-261, Mar. 2010.

[7] S. G. Ghalamestani, T. G. D. Hilgert, L. Vandevelde, J. J. J. Dirckx, and J. A. A. Melkebeek, "Magnetostriction Measurement by Using Dual Heterodyne Laser Interferometers," IEEE Trans. Magn., vol. 46, no. 2, pp. 505-508, Feb. 2010.

[8] M. J. Moser, T. Bretterklieber, H. Zangl, and G. Brasseur, "Strong and weak electric field interfering: Capacitive icing detection and capacitive energy harvesting on a $220-\mathrm{kV}$ high-voltage overhead power line," IEEE Trans. Ind. Electron., vol. 58, no. 7, pp. 25972604, 2011.

[9] G. Bucci, E. Fiorucci, F. Ciancetta, D. Gallo, C. Landi, and M. Luiso, "Embedded power and energy measurement system based on an analog multiplier," IEEE Trans. Instrum. Meas., vol. 62, no. 8, pp. 2248-2257, 2013.

[10] C. L. Holloway et al., "Broadband Rydberg atom-based electricfield probe for SI-traceable, self-calibrated measurements," IEEE Trans. Antennas Propag., vol. 62, no. 12, pp. 6169-6182, 2014.

[11] S. V. Gubbi and B. Amrutur, "All Digital Energy Sensing for Minimum Energy Tracking,” IEEE Trans. Very Large Scale Integr. Syst., vol. 23, no. 4, pp. 796-800, Apr. 2015.
[12] F. Adamo, F. Attivissimo, G. Cavone, A. Di Nisio, and M. Spadavecchia, "Channel characterization of an open source energy meter,” IEEE Trans. Instrum. Meas., vol. 63, no. 5, pp. 1106-1115, 2014.

[13] D. Lindenthaler and G. Brasseur, "Signal-Bandwidth Evaluation for Power Measurements in Electric Automotive Drives," IEEE Trans. Instrum. Meas., vol. 64, no. 6, pp. 1336-1343, 2015.

[14] P. C. Dias, F. J. O. Morais, M. B. de Morais Franca, E. C. Ferreira, A. Cabot, and J. A. Siqueira Dias, "Autonomous Multisensor System Powered by a Solar Thermoelectric Energy Harvester With Ultralow-Power Management Circuit," IEEE Trans. Instrum. Meas., vol. 64, no. 11, pp. 2918-2925, Nov. 2015.

[15] Y. Tsunoda et al., "A Small-Size Energy-Harvesting Electric Power Sensor for Implementing Existing Electrical Appliances Into HEMS,” IEEE Sens. J., vol. 16, no. 2, pp. 457-463, 2016.

[16] N. Alatawneh and P. Pillay, "Calibration of the Tangential Coil Sensor for the Measurement of Core Losses in Electrical Machine Laminations," IEEE Trans. Energy Convers., vol. 31, no. 2, pp. 413423, 2016.

[17] B. Qi, X. Zhao, and C. Li, "Methods to reduce errors for DC electric field measurement in oil-pressboard insulation based on Kerreffect," IEEE Trans. Dielectr. Electr. Insul., vol. 23, no. 3, pp. 1675$1682,2016$.

[18] C. Trigona, B. Andò, S. Baglio, R. La Rosa, and G. Zoppi, "Sensors for Kinetic Energy Measurement Operating on 'Zero-Current Standby,'” IEEE Trans. Instrum. Meas., vol. 66, no. 4, pp. 812-820, 2017.

[19] W. Yao, Y. Zhang, Y. Liu, M. J. Till, and Y. Liu, "Pioneer design of non-contact synchronized measurement devices using electric and magnetic field sensors," IEEE Trans. Smart Grid, vol. 9, no. 6, pp. 5622-5630, 2018.

[20] I. S. Kwon, J. Y. Na, H. Y. Lee, and B. W. Lee, "Determination of Threshold Electric Field for PPLP Specimen in Liquid Nitrogen Based on the Measurement of Electrical Conductivity," IEEE Trans. Appl. Supercond., vol. 28, no. 3, pp. 1-4, 2018.

[21] W. Liu, C. Tan, X. Dong, F. Dong, and Y. Murai, "Dispersed OilWater Two-Phase Flow Measurement Based on Pulse-Wave Ultrasonic Doppler Coupled with Electrical Sensors," IEEE Trans. Instrum. Meas., vol. 67, no. 9, pp. 2129-2142, 2018.

[22] S. Chamanian, S. Baghaee, H. Ulusan, O. Zorlu, E. Uysal-Biyikoglu, and H. Kulah, "Implementation of Energy-Neutral Operation on Vibration Energy Harvesting WSN," IEEE Sens. J., vol. 19, no. 8, pp. 3092-3099, 2019.

[23] G. Crotti et al., "Pantograph-To-OHL Arc: Conducted Effects in DC Railway Supply System," 9th IEEE Int. Work. Appl. Meas. Power Syst. AMPS 2018 - Proc., vol. 68, no. 2, pp. 3861-3870, 2018.

[24] M. Raeiszadeh and F. Taghipour, "Microplasma UV lamp as a new source for UV-induced water treatment: Protocols for characterization and kinetic study," Water Res., vol. 164, p. 114959, 2019.

[25] S. Mehran, M. Nikian, M. Ghazi, H. Zareiforoush, and I. Bagheri, "Experimental investigation and energy analysis of a solar-assisted fluidized-bed dryer including solar water heater and solar-powered infrared lamp for paddy grains drying," Sol. Energy, vol. 190, no. March, pp. 167-184, 2019.

[26] W. Do et al., "Effect of flash lamp annealing on electrical activation in boron-implanted polycrystalline Si thin films," Mater. Res. Bull., vol. 58, pp. 164-168, 2014. 
[27] C. De Santi et al., "Failure causes and mechanisms of retrofit LED lamps," Microelectron. Reliab., vol. 55, no. 9-10, pp. 1765-1769, 2015.

[28] M. Cai et al., "Step-stress accelerated testing of high-power LED lamps based on subsystem isolation method," Microelectron. Reliab., vol. 55, no. 9-10, pp. 1784-1789, 2015.

[29] C. Stegner, M. Dalsass, P. Luchscheider, and C. J. Brabec, "Monitoring and assessment of PV generation based on a combination of smart metering and thermographic measurement," Sol. Energy, vol. 163, no. February, pp. 16-24, 2018.

[30] W. L. Rodrigues Junior, F. A. S. Borges, A. F. da S. Veloso, R. de A. L. Rabêlo, and J. J. P. C. Rodrigues, "Low voltage smart meter for monitoring of power quality disturbances applied in smart grid," Measurement, vol. 147, p. 106890, 2019.

[31] S. Sureshkumar et al., "Utilization of eddy current flow meter for sodium flow measurement in FBRs," Nucl. Eng. Des., vol. 265, pp. 1223-1231, 2013.

[32] R. W. Herschy, "The uncertainty in a current meter measurement," Flow Meas. Instrum., vol. 13, no. 5-6, pp. 281-284, 2002.

[33] M. M. Othman, M. H. Ahmed, and M. M. A. Salama, "A novel smart meter technique for voltage and current estimation in active distribution networks," Int. J. Electr. Power Energy Syst., vol. 104, no. February 2018, pp. 301-310, 2019.

[34] D. B. Avancini, J. J. P. C. Rodrigues, S. G. B. Martins, R. A. L. Rabêlo, J. Al-Muhtadi, and P. Solic, "Energy meters evolution in smart grids: A review," J. Clean. Prod., vol. 217, pp. 702-715, 2019.
[35] F. Abate, M. Carratù, C. Liguori, and V. Paciello, "A low cost smart power meter for IoT,” Meas. J. Int. Meas. Confed., vol. 136, pp. 5966, 2019.

[36] G. van de Kaa, T. Fens, J. Rezaei, D. Kaynak, Z. Hatun, and A. Tsilimeni-Archangelidi, "Realizing smart meter connectivity: Analyzing the competing technologies Power line communication, mobile telephony, and radio frequency using the best worst method," Renew. Sustain. Energy Rev., vol. 103, no. January 2017, pp. 320-327, 2019.

[37] F. Ni, P. H. Nguyen, J. F. G. Cobben, H. E. Van den Brom, and D. Zhao, "Three-phase state estimation in the medium-voltage network with aggregated smart meter data," Int. J. Electr. Power Energy Syst., vol. 98, no. October 2017, pp. 463-473, 2018.

[38] Y. Wang, H. Qiu, Y. Tu, Q. Liu, Y. Ding, and W. Wang, "A review of smart metering for future Chinese grids," Energy Procedia, vol. 152, pp. 1194-1199, 2018.

[39] N. A. Funde, M. M. Dhabu, A. Paramasivam, and P. S. Deshpande, "Motif-based association rule mining and clustering technique for determining energy usage patterns for smart meter data," Sustain. Cities Soc., vol. 46, no. November 2018, p. 101415, 2019.

[40] C. Stegner, O. Glaß, and T. Beikircher, "Comparing smart metered, residential power demand with standard load profiles," Sustain. Energy, Grids Networks, vol. 20, p. 100248, 2019. 